\title{
Desain Sepeda Kampus Yang Menunjang Sistem Bike-Share Generasi Keempat (+) Untuk Kawasan Kampus Universitas Indonesia Dengan Konsep Unisex
}

\author{
Melvina Pangestika Putri, Bambang Tristiyono \\ Departemen Desain Produk, Fakultas Arsitektur Desain dan Perencanaan, \\ Institut Teknologi Sepuluh Nopember (ITS) \\ e-mail: gacombi@prodes.its.ac.id
}

\begin{abstract}
Abstrak-Sejak Juli 2007 kampus Universitas Indonesia telah menjadi pelopor "Bike to Campus" di Indonesia atau yang lebih dikenal dengan program "Sepeda Kuning". Sepeda kampus UI tersebar di seluruh area kampus dengan sistem peminjaman manual, sehingga harus ada petugas yang berjaga selama sepeda kampus ini beroperasi. Sepeda kampus UI masih menggunakan desain sepeda gunung yang umum dijual di pasaran, sehingga kurang cocok untuk pengguna wanita terutama yang memiliki ukuran tubuh kecil saat mengendarai. Sepeda kampus UI ini belum memiliki karakter desain tersendiri sehingga belum menunjang kebutuhan masyarakat kampus ketika membawa barang-barang. Sepeda kampus UI ini juga masih belum memiliki konsep desain yang sesuai dengan keadaan pengguna di area kampus. Maka dari itu perlu dilakukan riset untuk memperbaiki sepeda kampus UI baik dari segi karakter desain dan konsep desain yang diusung. Dalam penelitian ini, untuk menyelesaikan masalah tersebut maka konsep yang ditawarkan adalah unisex. Karena sepeda kampus ini nantinya akan digunakan oleh wanita maupun pria dari semua kalangan usia sehingga akan cocok digunakan untuk semua gender terutama dari desain frame sepeda. Desain frame sepeda ini sendiri juga diambil dari bentuk daun sebagai salah satu simbol Eco Green. Dengan karakter desain bentuk frame ini diharapkan masyarakat dapat membedakan dengan sepeda kampus lainnya. Adanya proyek sepeda kampus dengan sistem bike share berkonsep unisex ini, diharapkan dapat lebih meningkatkan peringkat Universitas Indonesia dalam kategori Green Matic.
\end{abstract}

Kata Kunci-bike-share, gaya hidup, ui green matic.

\section{PENDAHULUAN}

$\mathrm{U}$ NIVERSITAS Indonesia merupakan salah satu universitas mendukung gerakan Green Matic di Indonesia. Universitas Indonesia (UI) menempati peringkat ke23 sebagai kampus terhijau dunia versi UI GreenMetricWorld University Rankings 2017. Untuk mendukung green matic, Universitas Indonesia menyediakan transportasi umum yang terintegrasi dengan hampir semua fakultas, salah satunya adalah "Sepeda Kuning" yang mulai beroperasi pada Juli 2007. Sepeda Kuning sendiri memiliki jalur yang terpisah dari jalan utama, sehingga memungkinkan pengguna untuk leluasa berkendara. Universitas Indonesia pernah mendapat predikat sebagai Universitas yang memiliki jalur sepeda terpanjang di dunia yang mencapai $25 \mathrm{~km}$.

Predikat kampus terhijau di Indonesia berhasil diraih oleh Universitas Indonesia yang menduduki posisi ke-33 di dunia (skor 6.157) pada tahun 2015 pada acara UI Green Matic. Kampus Universitas Indonesia menjadi role model bike share untuk kampus lain dan kota Jakarta sendiri.

Meskipun telah berlangsung sekian lama, sepeda kampus UI ini memiliki beberapa kekurangan, yaitu dari segi desain sepeda, konsep desain, dan sistem keamanannya. Sepeda kampus UI ini menggunakan desain sepeda gunung yang umum dijual di pasaran, sehingga jika dilihat dari fungsinya kurang cocok karena seperti yang kita tahu sepeda ini digunakan di area kampus. Sepeda kampus UI ini tersebar di seluruh area kampus dengan sistem peminjaman manual tanpa dilengkapi dengan kuncian, sehingga harus ada petugas yang berjaga selama sepeda kampus ini beroperasi. Sehingga dapat menimbulkan aksi vandalisme dan penyalahgunaan fungsi sepeda kampus.

Salah satu konsep yang ditawarkan untuk menyelesaikan sepeda kampus UI dengan permasalahan aksesbilitas adalah unisex. Produk-produk dengan konsep unisex sudah banyak ditemukan di pasaran karena dapat digunakan baik untuk wanita maupun pria, diantaranya yaitu produk 'Ardiles For-All' diberi label unisex karena dirancang khusus agar dapat digunakan dan cocok untuk pria ataupun wanit. Native shoes dirancang unisex untuk membuatnya mudah bagi siapa saja yang akan memakainya. Native shoes bertujuan agar dapat digunakan melampaui jenis kelamin, usia dan klasifikasi lain yang menentukan yang harus mengenakan gaya tertentu. Native shoes tidak ingin memberitahu siapa pun bahwa pengguna dapat atau tidak dapat mengenakan aturan warna tertentu hanya karena itu biasanya warna 'wanita' atau 'pria'.

Dalam riset ini, desain frame sepeda diambil dari bentuk daun sebagai salah satu simbol Eco Green. Dengan karakter desain bentuk frame ini diharapkan masyarakat dapat membedakan dengan sepeda kampus lainnya yang sekaligus dijadikan sebagai brand identity. Adanya proyek sepeda kampus dengan sistem bike share berkonsep unisex ini, diharapkan dapat lebih meningkatkan peringkat Universitas Indonesia dalam kategori Green Matic. 


\section{II.METODOLOGI}

\section{A. Literature Review}

Literatur review dibutuhkan untuk mencari jurnal yang terkait dengan proyek yang sedang dikerjakan. Jurnal ini dapat berupa apa yang sudah pernah dilakukan oleh orang lain, atau masih berupa rencana jangka panjang. Dari hasil review beberapa literatur ini maka didapatkan beberapa hal yaitu:

1. Kondisi bike share yang telah sukses di negara lain

2. Sistem peminjaman dan sistem kuncian yang digunakan pada bike share yang ada

3. Titik lokasi yang tepat untuk menentukan lokasi bike share

4. Sepeda kampus yang ada di Indonesia

5. Sistem peminjaman dan kuncian dari sepeda kampus yang telah ada

Beberapa hasil diatas dapat juga dijadikan acuan dalam tinjauan pustaka.

\section{B. Survey}

Survey dilakukan untuk mengetahui kondisi lapangan terutama kondisi sepeda kampus eksisting di kampus Universitas Indonesia. Hasil dari survey ini menjadi data primer yang akan digunakan, serta digunakan juga untuk mengonfirmasi masalah yang ada di jurnal dengan yang ada di lapangan.

Survey ini dilakukan tiga kali, yaitu pada:

1. Waktu pelaksanaan: Jumat, 7 Juli 2017 pukul 09:00 - 14:00

Lokasi: Kampus Universitas Indonesia Depok Daftar pengamatan:

a. Kondisi sepeda kampus UI

b. Sistem peminjaman dan kuncian sepeda kampus UI

c. Ukuran dan jenis sepeda yang digunakan

d. Bentuk dari docking UI

e. Luas stasiun sepeda kampus UI

2. Waktu pelaksanaan: Rabu, 2 Agustus 2017 pukul 11:00 - 14:00

Lokasi : Kampus Universitas Indonesia Depok Daftar pengamatan :

a. Titik lokasi yang akan digunakan pada bike share, sesuai dengan faktor-faktor tertentu

b. Titik lokasi yang memungkinkan untuk digunakan sewaktu-waktu apabila ada acara tertentu

c. Luas stasiun yang akan digunakan untuk bike share nanti

3. Waktu pelaksanaan : Senin, 11 Juni 2018 pukul 10:00 - 15:00

Lokasi : Kampus Universitas Indonesia Depok Daftar pengamatan :

a. Populasi busana pengguna wanita yang umum digunakan di area kampus

b. Jenis dan bahan rok yang umum digunakan wanita khususnya untuk yang berjilbab supaya desain sepeda yang dibuat memungkinkan untuk 2 digunakan untuk semua jenis kelamin dengan berbagai latar belakang.

\section{Eksplorasi Ide}

Sketsa brainstorming: hasil dari data primer dan sekunder disatukan kemudian diproses kembali melalui sketsa-sketsa yang dapat memunculkan ide baru.

\section{D.Pemilihan Desain Alternatif}

Hasil dari eksplorasi ide dipilih dan disimpulkan menjadi desain alternatif yang sesuai dengan indikator yang sesuai berdasarkan hasil riset dan desain.

\section{E. Studi dan Analisis Desain}

Alternatif yang telah dipilih dikembangkan menjadi lebih detail dengan bantuan riset-riset yang telah dilakukan dan sesuai dengan konsep desain seperti aspek teknis, bentuk, dan semacamnya.

\section{F. Digital Modelling}

Desain yang terpilih kemudian disimulasikan secara digital untuk memudahkan mendapatkan alternatif hingga terwujud desain final.

\section{G.Prototipe}

Final desain yang terpilih direalisasikan dengan skala asli yaitu 1:1 menggunakan material aslinya.

\section{KONSEP DAN ANALISIS}

\section{A. Analisis Konsep Desain}

Melalui brainstorming, konsep desain didapatkan berdasarkan data aktivitas dan kebutuhan penumpang. Masingmasing konsep dideskripsikan secara objektif sehingga didapat ketentuan capaian desain yang perlu dipenuhi.

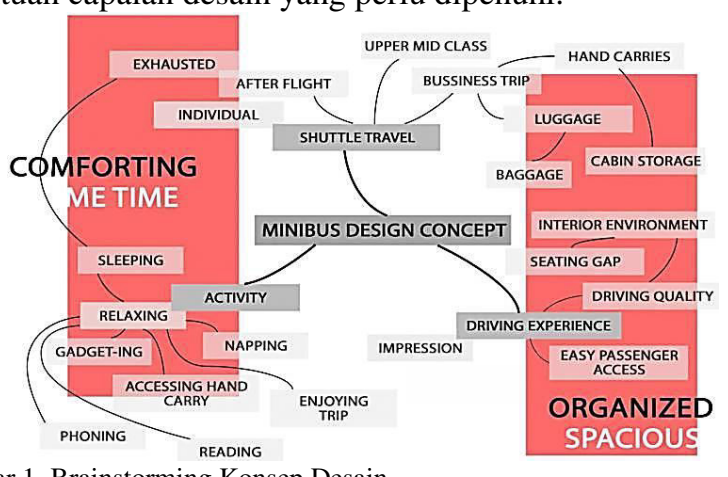

Gambar 1. Brainstorming Konsep Desain.

Dua konsep tersebut dijelaskan lebih lanjut sebagai berikut.

\section{1) Comforting}

Konsep comforting diarahkan pada kualitas berkendara yang dialami para penumpang selama perjalanan. Konsep diterapkan pada suasana desain interior secara keseluruhan sehingga dapat memberikan pengalaman berkendara yang berkesan relaxing.

\section{2) Organized}

Konsep organized diarahkan pada pengkonfigurasian dan zonasi interior secara menyeluruh demi memenuhi kebutuhan user yang spesifik. Organized yang diterapkan mencakup konfigurasi kursi, bagasi, storage interior, hingga akses koridor keluar masuk penumpang. 
Tabel 1.

Objective Tree Concept

\begin{tabular}{|c|c|c|}
\hline \multirow{6}{*}{ Comforting } & \multirow{3}{*}{ Driving Experience } & Seating Ergonomics \\
\hline & & Window Vision \\
\hline & & Personal Passenger Feature \\
\hline & \multirow{3}{*}{$\begin{array}{c}\text { Relaxing } \\
\text { Environment }\end{array}$} & Shape Harmony \\
\hline & & Color Harmony \\
\hline & & Indirect Lighting \\
\hline \multirow{5}{*}{ Organized } & \multirow{3}{*}{$\begin{array}{c}\text { Interior } \\
\text { Konfiguration }\end{array}$} & Seat and Row Gap \\
\hline & & Overhead Baggage \\
\hline & & Interior Storage \\
\hline & \multirow{2}{*}{ Interior zoning } & Passenger Access \\
\hline & & Spacious Baggage Space \\
\hline
\end{tabular}

\section{B. Analisis User}

Meliputi psikografis konsumen, rumusan kebutuhan dan fitur, persona, serta barang bawaan pengguna layanan jasa shuttle travel rute bandara. Kesimpulan fitur yang perlu untuk diaplikasikan dapat dilihat pada Tabel 2.

\section{C.Analisis Zoning}

Dengan semua data dan kebutuhan desain yang diperoleh, pemilihan sasis berdasar komparasi sasis yang memungkinkan untuk digunakan dan pilihan jatuh pada Mitsubishi FE 84G.

\section{D.Analisis Dimensi Passenger Seat}

Analisis ini meliputi penetapan dimensi kursi, dan konfigurasinya. Dimensi kursi dihitung dengan data-data dari penelitian yang telah dilakukan sebelumnya.

\section{Tabel 2.}

Perumusan Fitur Interior

\begin{tabular}{|c|c|c|c|}
\hline Konsumen & & " Kebutuhan & Fitur \\
\hline \multirow[t]{2}{*}{$\begin{array}{l}\text { Usia } \\
\text { Produktif }\end{array}$} & Laki-laki & $\begin{array}{l}\text {-Charging Gadget } \\
\text {-Kesan Prestige } \\
\text {-Kabin Tidak } \\
\text { Bising } \\
\text {-Sinyal Internet } \\
\text {-Kenyamanan }\end{array}$ & $\begin{array}{l}\text {-Electrical Port } \\
\text {-Desain Prestige } \\
\text {-Kedap Suara } \\
\text {-Free Wi-fi } \\
\text {-Seat Armrest }\end{array}$ \\
\hline & Wanita & $\begin{array}{l}\text {-Membaca } \\
\text {-Nilai Privasi } \\
\text {-Barang Bawaan } \\
\text {-Kursi Nyaman } \\
\text {-Pemandangan } \\
\text { Luar }\end{array}$ & $\begin{array}{l}\text {-Lampu Baca } \\
\text {-Gap Seat/Row } \\
\text {-Spacious Baggage } \\
\text {-Ergonomi Kursi } \\
\text {-Panoramic Roof }\end{array}$ \\
\hline \multirow[t]{2}{*}{$\begin{array}{l}\text { Usia } \\
\text { Lanjut }\end{array}$} & Laki-laki & $\begin{array}{l}\text {-Interior Nyaman } \\
\text {-Istirahat } \\
\text {-Penerangan Kabin } \\
\text {-Membawa Minum } \\
\text {-Bekerja }\end{array}$ & $\begin{array}{l}\text {-Kualitas Interior } \\
\text {-Driving Quality } \\
\text {-Interior Lighting } \\
\text {-Cup Holder } \\
\text {-Fold-out Table }\end{array}$ \\
\hline & Wanita & $\begin{array}{l}\text {-Kenyamanan } \\
\text { Kursi } \\
\text {-Barang Bawaan } \\
\text {-Komponen } \\
\text { Interior } \\
\text {-Storage Memadai } \\
\text {-Nilai Privasi } \\
\text {-Sirkulasi Udara }\end{array}$ & $\begin{array}{l}\text {-Adjustable Seat } \\
\text {-Konfigurasi } \\
\text { Bagasi } \\
\text {-BSR Compliance } \\
\text {-Storage } \\
\text {-Konfigurasi Kursi } \\
\text {-Personal AC } \\
\text { Knob }\end{array}$ \\
\hline
\end{tabular}

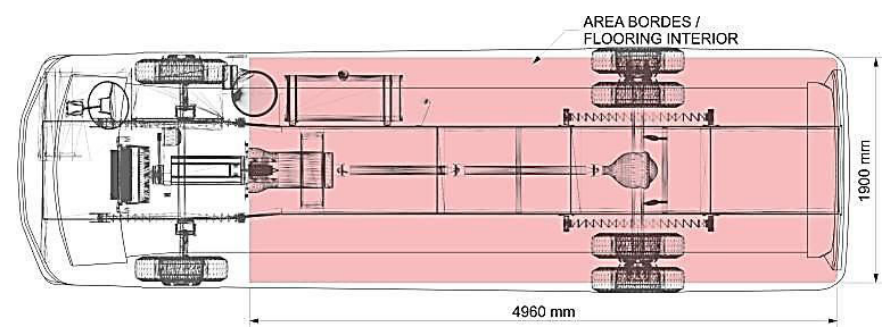

Gambar 2. Analisis Zoning Sasis Mitsubishi FE 84G.

Tabel 3.

Data Anthropometri

\begin{tabular}{clcc}
\hline \hline No & Data & Persentil & Ukuran \\
\hline 1 & Tinggi Popliteal & $50 \%$ & $440 \mathrm{~mm}$ \\
2 & Pantat Popliteal & $50 \%$ & $435 \mathrm{~mm}$ \\
3 & Lebar Bahu & $50 \%$ & $440 \mathrm{~mm}$ \\
4 & Tinggi Duduk Santai & $95 \%$ & $850 \mathrm{~mm}$ \\
5 & Tinggi Siku Posisi Duduk Santai & $50 \%$ & $250 \mathrm{~mm}$ \\
6 & Jarak Siku ke Tangan & $50 \%$ & $255 \mathrm{~mm}$ \\
7 & Jarak Pantat ke Lutut & $95 \%$ & $590 \mathrm{~mm}$ \\
\hline \hline
\end{tabular}

Tabel 4.

Formulasi Dimensi

\begin{tabular}{clcc}
\hline \hline No & Dimensi & Formula & Ukuran \\
\hline 1 & Tinggi Alas Kursi & TP + TOL & $450 \mathrm{~mm}$ \\
2 & Panjang Alas Kursi & PP & $430 \mathrm{~mm}$ \\
3 & Lebar Alas Kursi & LB & $440 \mathrm{~mm}$ \\
4 & Tinggi Sandaran Kursi & TDS & $850 \mathrm{~mm}$ \\
5 & Tinggi Sandaran Tangan & TSS & $250 \mathrm{~mm}$ \\
6 & Panjang Sandaran Tangan & JST & $265 \mathrm{~mm}$ \\
7 & Jarak Antar Kursi & JPL - PP + TOL & $200 \mathrm{~mm}$ \\
\hline \hline
\end{tabular}
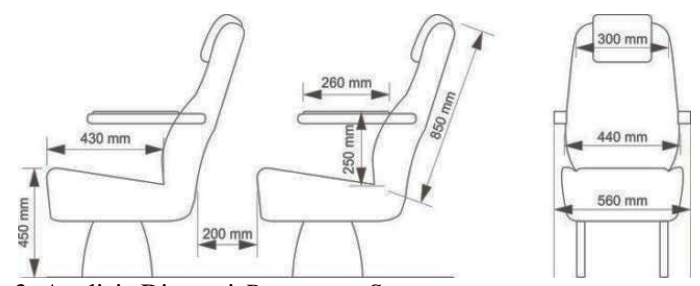

Gambar 3. Analisis Dimensi Passenger Seat.

\section{E. Analisis Konfigurasi Kursi berdasar Teori Proxemics}

Dari dimensi yang telah didapat dari analisis sebelumnya, pengkonfigurasian jarak antar kursi dan row dilakukan dengan mempertimbangkan aspek nilai proxemics.

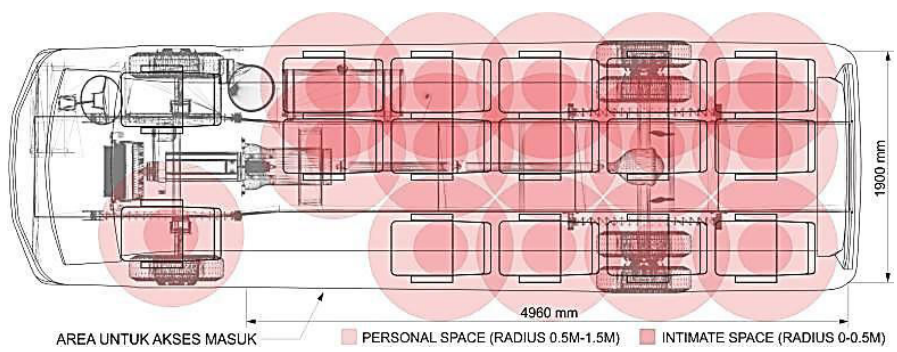

Gambar 4. Analisis Konfigurasi Kursi Berdasar Teori Proxemics.

\section{F. Analisis Akses Penumpang}

Analisis akses penumpang dilakukan dengan mempertimbangkan kemudahan akses naik-turun kendaraan. Dimensi koridor juga berdasarkan dimensi yang telah didapatkan dari analisa dimensi kursi dan konfigurasi kursi. 


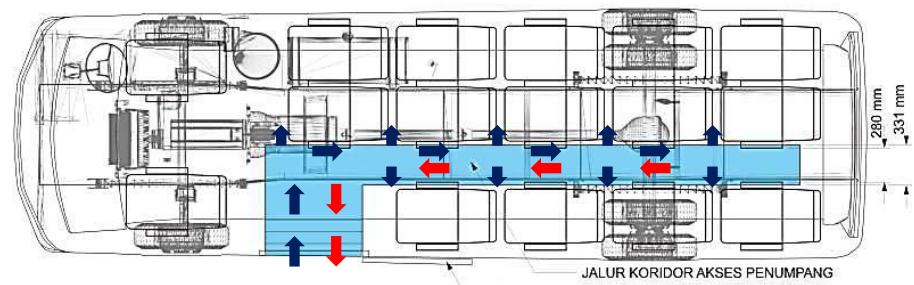

Gambar 5. Analisis Akses Penumpang.

\section{G.Analisis Konfigurasi Bagasi Kabin}

Analisis ini mengikuti dimensi hand-carry barang bawaan penumpang sesuai dengan aturan maskapai penerbangan. Dimensi maksimumnya ialah 560x360x230 mm.

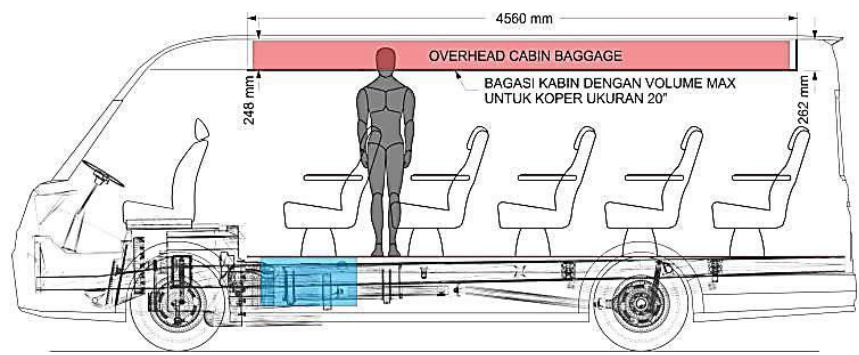

Gambar 6. Analisis Konfigurasi Bagasi Kabin Tampak Samping.

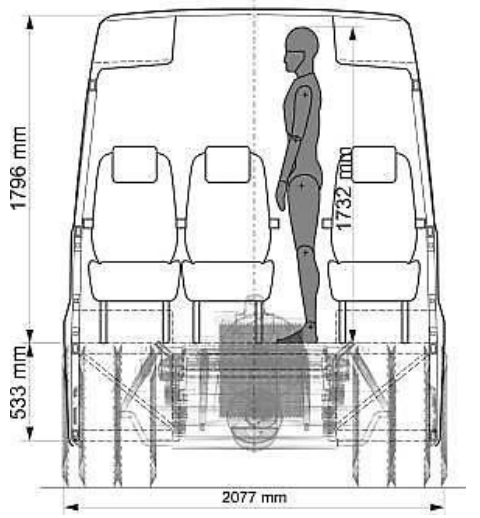

Gambar 7. Cross Section Analisis Konfigurasi Bagasi Kabin.

\section{A. Analisis Passenger Window Vision}

Analisis ini dilakukan karena kondisi user pra- dan pascapenerbangan yang cenderung jenuh dan kelelahan. Treatment yang diberikan kepada user tersebut ialah suasana relaxing dimana user dapat merasakan driving experience baru dengan adanya panoramic roof dan passenger window berdimensi besar.

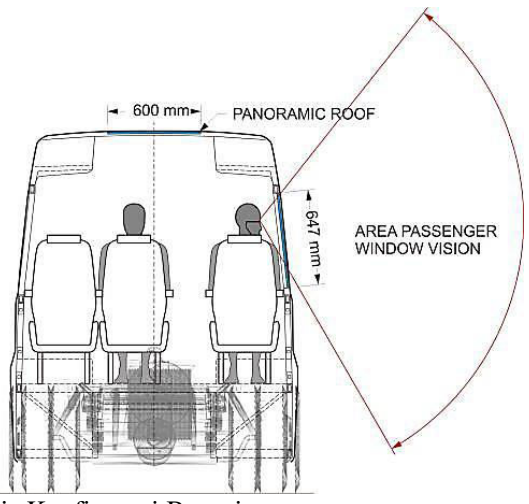

Gambar 8. Analisis Konfigurasi Bagasi.

\section{HASIL DESAIN}

\section{A. Eksplorasi Sketsa}

Eksplorasi sketsa diawali dengan thumbnail sketch bentuk dan proporsi yang mengacu dengan analisa yang telah dilakukan baik teknis dan visual.

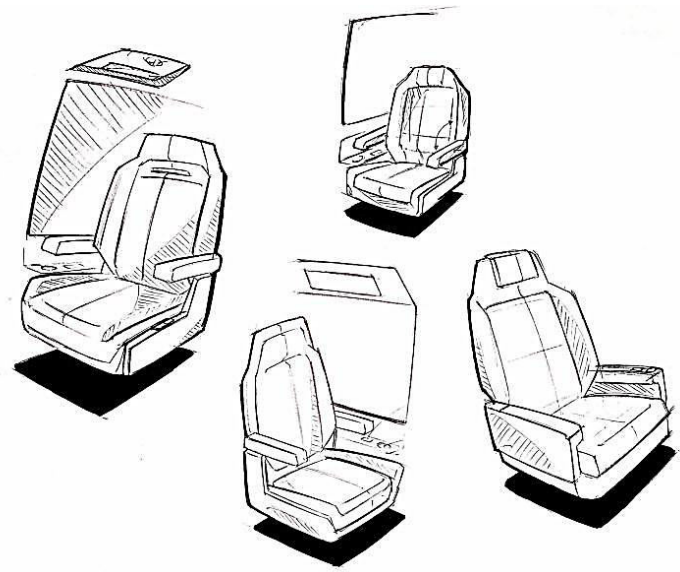

Gambar 9. Sketsa Ideasi Bentuk dan Proporsi.

\section{B. Desain Alternatif}

Sketsa alternatif interior dibuat dengan bentukan, proporsi dan batasan teknis yang telah didapat dari berbagai analisa. Tiga alternatif desain interior dirancang berdasarkan tiga image board yang telah dibuat sebelumnya.

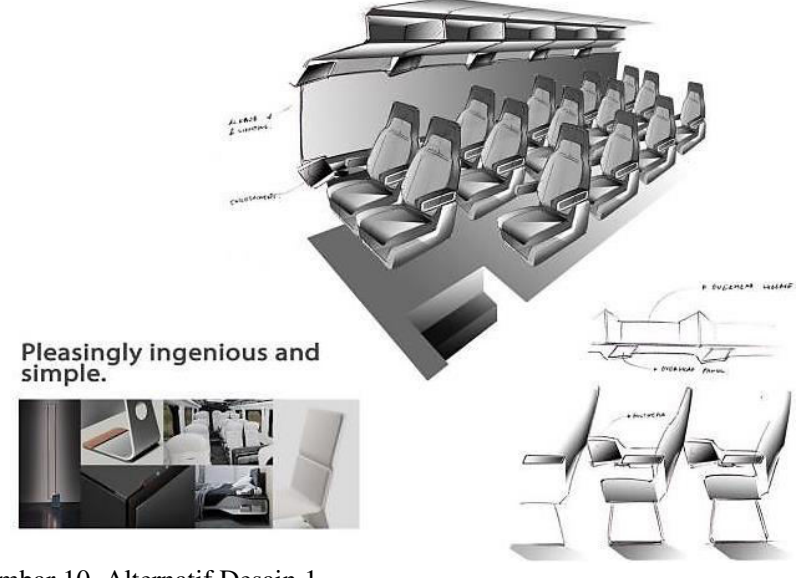

Gambar 10. Alternatif Desain 1.

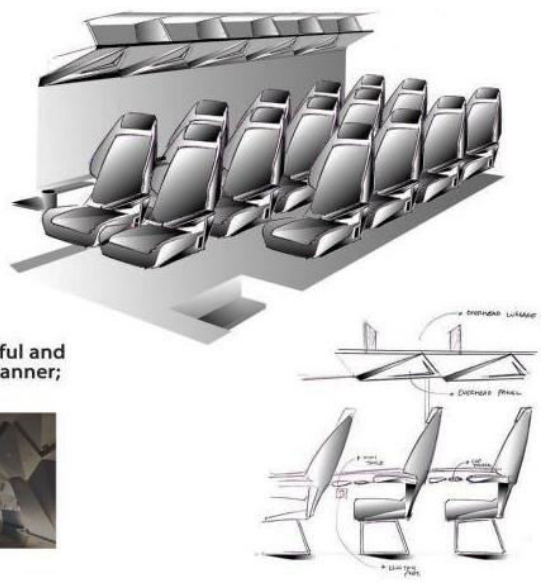

Gambar 11. Alternatif Desain 2. 


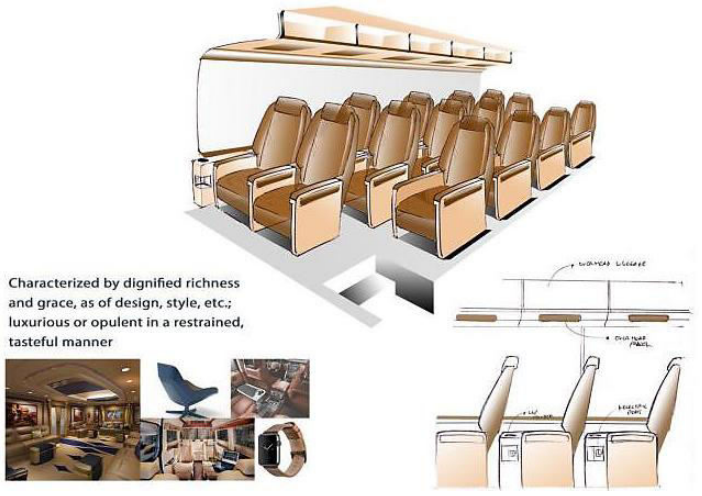

Gambar 12. Alternatif Desain 3.

Dari sketsa alternatif interior yang telah dibuat, dipilih satu desain akhir dimana desain tersebut memiliki nilai dari scoring yang dilakukan sebagai berikut:

Tabel 5.

Scoring Pemilihan Desain Alternatif

\begin{tabular}{|c|c|c|c|c|c|c|c|c|c|}
\hline \multirow[b]{2}{*}{ No } & \multicolumn{3}{|c|}{ Parameter } & \multicolumn{2}{|c|}{ Alt 1} & \multicolumn{2}{|c|}{ Alt 2} & \multicolumn{2}{|c|}{ Alt 3} \\
\hline & Item & W & $\begin{array}{c}\text { Deskrips } \\
\text { i }\end{array}$ & $\begin{array}{c}\mathrm{Ra} \\
\text { te }\end{array}$ & $\begin{array}{l}\text { To } \\
\text { tal }\end{array}$ & $\begin{array}{l}\mathrm{Ra} \\
\text { te }\end{array}$ & $\begin{array}{l}\text { To } \\
\text { tal }\end{array}$ & $\begin{array}{c}\mathrm{Ra} \\
\text { te }\end{array}$ & $\begin{array}{l}\text { To } \\
\text { tal }\end{array}$ \\
\hline 1 & $\begin{array}{l}\text { Relaxing } \\
\text { Feeling }\end{array}$ & 0.5 & $\begin{array}{l}\text { Suasana } \\
\text { Interior }\end{array}$ & 3 & 1.5 & 1 & 0.5 & 3 & 1.5 \\
\hline 2 & $\begin{array}{l}\text { Color } \\
\text { Harmony }\end{array}$ & 0.3 & $\begin{array}{l}\text { Part dan } \\
\text { Panel }\end{array}$ & 4 & 1.2 & 4 & 1.2 & 3 & 0.9 \\
\hline 3 & $\begin{array}{l}\text { Shape } \\
\text { Harmony }\end{array}$ & 0.1 & $\begin{array}{l}\text { Part dan } \\
\text { Panel }\end{array}$ & 3 & 0.3 & 4 & 0.4 & 4 & 0.4 \\
\hline 4 & $\begin{array}{l}\text { Compact- } \\
\text { ness }\end{array}$ & 0.1 & $\begin{array}{l}\text { Assembly } \\
\text { dan } \\
\text { Prod, }\end{array}$ & 4 & 0.4 & 3 & 0.3 & 3 & 0.3 \\
\hline & Total & 1 & & & 3.4 & & 2.4 & & 3.1 \\
\hline
\end{tabular}

Keterangan:

1=Sangat Kurang; 2=Kurang; 3=Cukup; 4=Baik; 5=Sangat Baik

Penilaian skor 1-5 dari pemilihan desain alternatif berdasarkan parameter yang memiliki nilai kepentingannya masing-masing:

1) Relaxing Feeling (0.5)

Treatment atau driving experience yang ditawarkan dari suasana desain interior yang dapat membuat penumpang rileks dan beristirahat dengan baik merupakan aspek terpenting dalam perancangan desain interior minibus shuttle travel rute bandara.

\section{2) Color Harmony (0.3)}

Kepaduan warna dari part dan panel interior merupakan impresi pertama yang dirasakan penumpang. Tone warna gradasi black-light grey merupakan tone yang memiliki kesan ringan dan santai.

3) Shape Harmony (0.1)

Kepaduan bentuk dari part dan panel interior merupakan impresi selanjutnya yang dirasakan penumpang. Bentukan simple dan tidak rumit dapat memberikan kesan relaxing bagi penumpang.

\section{4) Compactness $(0.1)$}

Parameter ini berhubungan dengan kemudahan assembly part dimana juga berhubungan dengan bentukan shape harmony yang tidak rumit. Selain itu, parameter ini juga mencakup efektivitas ruang secara dimensional.

Keterangan Skor:

\section{5) Alternatif 1}

Dari segi driving experience yang ditawarkan, alternatif ini menawarkan suasana yang cukup relaxing (3). Untuk kepaduan warna dengan tone black-light grey memiliki nilai yang baik (4). Dari segi kepaduan bentuk terbilang cukup namun tepat sasaran dengan bentukannya yang tidak rumit (3) sehingga memiliki nilai baik pada parameter compactness (4). 6) Alternatif 2

Alternatif ini memiliki desain yang terbilang tense dimana ada driving experience baru yang ditawarkan, namun bentukannya yang rumit membuat nilai suasana relaxing yang sangat kurang (1). Untuk kepaduan warna dengan tone blacklight grey memiliki nilai yang baik (4). Dari segi kepaduan bentuk terbilang baik (4) namun memiliki nilai cukup pada parameter compactness karena bentukannya yang rumit (3).

7) Alternatif 3

Alternatif ini memiliki desain yang memiliki driving experience dengan suasana relaxing yang cukup (3). Untuk kepaduan warna dengan tone beige, alternatif ini memiliki nilai yang cukup (4). Dari segi kepaduan bentuk terbilang baik (4) namun bernilai cukup pada parameter compactness karena memiliki part yang besar dan banyak (3).

\section{C.Pengembangan Desain}

\section{1) Detil Passenger Seat}

Material passenger seat menggunakan kulit sintetis berwarna hitam pada cover dan bantalan armrest, serta material plastik dengan finishing matte black pada komponen part berbahan fiber / plastik. Detil aksen pada passenger seat menggunakan finishing polished sehingga menambah kesan elegant.
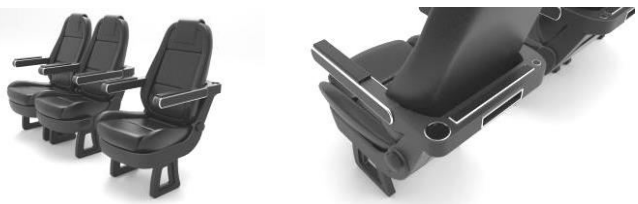

Gambar 13. Gambar Detil Passenger Seat.

\section{2) Detil Interior Cabin}

Tone warna pada interior kabin penumpang merupakan gradasi dari hitam ke light grey. Material flooring ialah pvc laminasi bludru berwarna hitam, sedangkan koridor akses yang luas dilapisi karpet berwarna abu tua. Aksen-aksen baik pada tangga akses, dinding dan bagian atap menggunakan finishing polished sehingga menambah impresi mewah. Dari segi konfigurasi storage, interior ini memiliki overhead baggage yang dapat menampung barang bawaan penumpang dengan ukuran maksimal koper 20 inch.

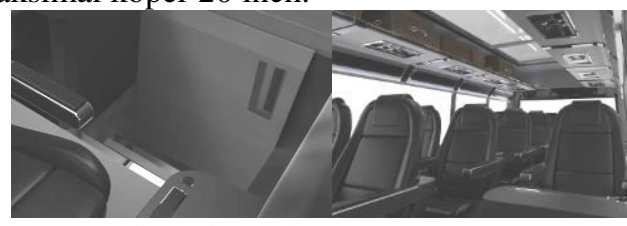

Gambar 14. Gambar Detil Kabin Interior.

\section{3) Fitur Panoramic Roof}

Bagian atap terdapat panoramic roof. Fitur ini dapat memberikan driving experience baru dimana penumpang memiliki akses visual terhadap alam. Fitur ini dapat 
memberikan suasana relaxing yang menjadi alternatif kegiatan selain beristirahat saat perjalanan berlangsung.

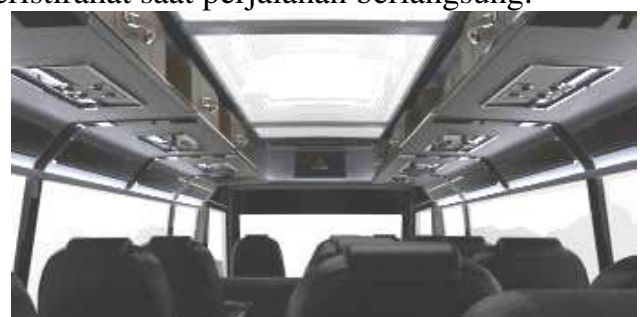

Gambar 15. Gambar Fitur Panoramic Roof.

4) Fitur Indirect Interior Lighting

Pencahayaan interior menggunakan iluminasi lampu LED sehingga suasana di dalam kabin nyaman untuk beristirahat.

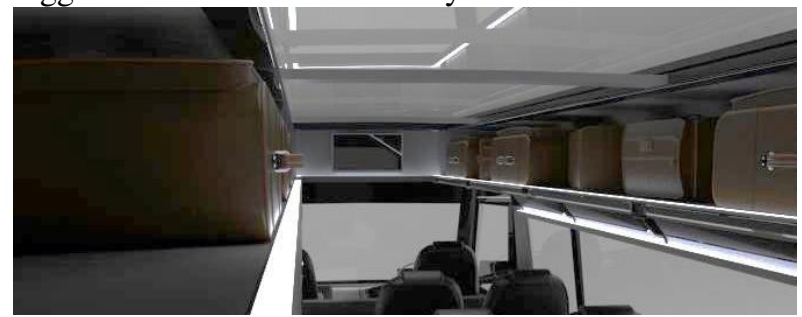

Gambar 16. Gambar Fitur Pencahayaan Interior.

\section{5) Fitur Passenger Seat}

Fitur fold-out tray table dapat digunakan penumpang untuk menunjang berbagai aktivitasnya. Meja lipat memiliki dimensi yang cukup untuk penempatan sebuah laptop atau bahkan untuk menulis dan makan. Tiap kursi juga dilengkapi dengan cup holder. USB charging port dapat digunakan untuk memenuhi kebutuhan daya listrik.

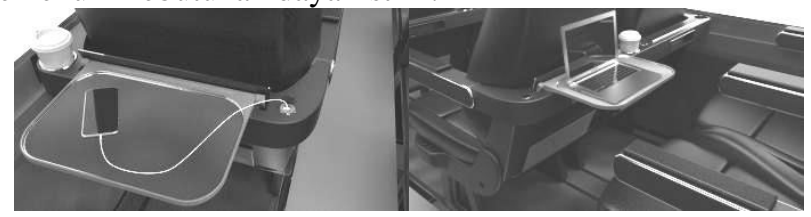

Gambar 17. Gambar Rendering Passenger Seat.

\section{D.Final Desain}

Suasana interior minibus ini memiliki konsep comforting, dimana penumpang dapat beristirahat dengan nyaman. Terdapat suntex blind (tirai jendela) berbahan vinyl-coated polyester pada setiap jendela penumpang yang dapat dibukatutup secara personal. Proporsi jendela penumpang dan panoramic roof yang besar memberikan nuansa natural sehingga pengalaman berkendara akan terasa sangat santai dan membuat penumpang rileks. Demi menjaga cahaya matahari yang masuk, penggunaan kaca film berteknologi tinggi digunakan.

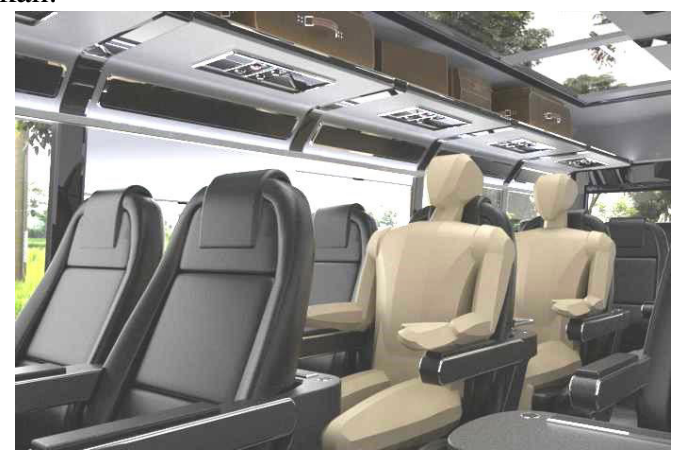

Gambar 18. Gambar Rendering Suasana Interior 1.

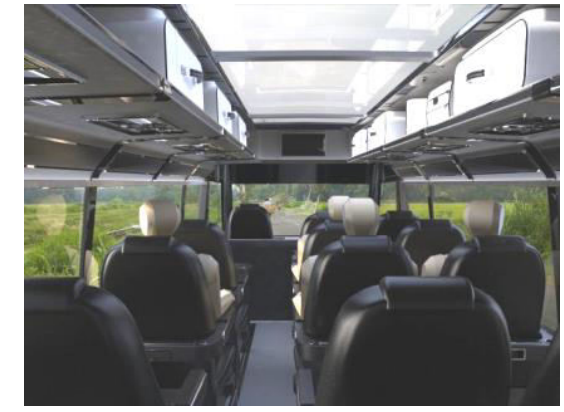

Gambar 19. Gambar Rendering Suasana Interior 2.

\section{KESIMPULAN}

Berdasarkan penelitian yang telah dilakukan, didapatkan kesimpulan dari pengembangan Desain Interior Minibus untuk Shuttle Travel Rute Bandara ialah sebagai berikut:

\section{A. Konsumen shuttle travel dalam pengembangan desain interior minibus}

Konsumen shuttle travel rute bandara memiliki berbagai macam kebutuhan spesifik dimana setelah penilitian ini dilakukan, kebutuhan spesifik tersebut dapat dipenuhi dengan pengimplementasian beberapa fitur dalam pengembangan desain interior minibus ini, seperti:

1) Konfigurasi

a. Jarak antar kursi penumpang yang memenuhi nilai proxemics.

b. Akses pintu dan koridor penumpang yang luas dan mudah diakses.

c. Dimensi storage pada interior yang sesuai dengan kebutuhan.

d. Dimensi bagasi yang sesuai dengan kebutuhan.

2) Fitur Penumpang

a. Ergonomic Passenger Seat with Armrest

b. Fold-out Tray Table

c. Cup Holder

d. USB Electrical Port

e. Free Wi-Fi

f. Personal Storage

g. Personal Adjustable AC Knob

h. Personal Reading Lamp

$i$. Personal Suntex Blind

\section{B. Konsumen shuttle travel kondisi post-flight}

Konsumen shuttle travel rute bandara dengan kondisi postflight membutuhkan desain interior kendaraan dengan perlakuan atau treatment khusus. Treatment tersebut berupa suasana interior dengan driving experience yang secara psikologis dapat memenuhi ekspektasi user, yaitu:

1. Penerapan warna dan material yang nyaman dan hangat.

2. Penerapan bentuk komponen interior yang simple dan tidak rumit.

3. Penerapan iluminasi pada pencahayaan interior sehingga nyaman untuk beristirahat.

4. Penerapan panoramic roof yang menimbulkan suasana relaxing ketika melihat pemandangan alam.

5. Penerapan fitur penumpang personal dan free $\mathrm{Wi} ; \mathrm{Fi}$ yang dapat menunjang aktivitas bekerja. 


\section{DAFTAR PUSTAKA}

[1] R. Aminy, "Desain Docking Bike-Share Generasi Ketiga Di Kawasan Wisata Kota Bandung," Institut Teknologi Bandung, 2016.

[2] M. E. Khuluqi, "Bike Sharing System Untuk Mendukung 'Hari Jumat Bersepeda," Universitas Padjajaran, 2016.

[3] D. Kurniawan, "Desain Sepeda Kampus sebagai Sarana Penunjang Mobilitas Mahasiswa di dalam Kampus, Studi Kasus: Institut Teknologi Sepuluh Nopember Surabaya," Institut Teknologi Sepuluh Nopember Surabaya, 2012.

[4] J. Panero and M. Zelnik, Buku Dimensi Manusia dan Ruang Interior. .
[5] M. Rani and V. O. P., "Smart Bike Sharing System to Make the City Even Smarter," Indian Institute of Information Technology Allahabad, 2016.

[6] B. Suhadri, Perancangan Sistem Kerja dan Ergonomi Industri Jilid 1 untuk SMK. Jakarta: Direktorat Pembinaan Sekolah Menengah Kejuruan, Direktorat Jenderal Manajemen Pendidikan Dasar dan Menengah, Departemen Pendidikan Nasional, 2008.

[7] A. R. Sutalaksana and J. H. Tjakraatmadja, Teknik Perancangan Sistem Kerja. Bandung: ITB, 2006.

[8] A. Nurrewa, "Kerja Profesi Desain Produk," 2015. 